\title{
Prevalence of Head and Neck Cancer in Gilan Province, Iran: A 10-Year Study
}

\author{
Shahsavari $\mathbf{F}^{1}$, Jolehar $\mathbf{M}^{1^{*}}$, Nikpasand $\mathbf{M}^{2}$ \\ ${ }^{1}$ Assistant professor, oral and Maxillofacial Pathology Dept., Dental Branch of Tehran, Islamic Azad University, Tehran, Iran \\ ${ }^{2}$ Dentist, Tehran, Iran
}

\begin{tabular}{l}
\hline ARTICLE INFO \\
\hline Article Type \\
Short communicaiton \\
\hline Article History \\
Received:Apr 2017 \\
Accepted: May 2017 \\
ePublished: Jun 2017
\end{tabular}

Keywords:

Head and Neck Neoplasms; Basal cell carcinoma; Carcinoma,

Squamous Cell of Head and Neck

\section{ABSTRACT}

Background and Aim: Head and neck cancers are the tenth most common cancers worldwide. Since these cancers can cause severe complications and mortality, early diagnosis and investigation of their prevalence in various regions may be life-saving. Therefore, this study evaluated the prevalence of head and neck cancer over a 10-year period in Gilan province, Iran.

Methods and Materials: This is a retrospective and descriptive study based on the data collected from the Cancer Registry Center of Gilan province, Iran, during 19992008. The data included age, sex, cancer type, and the location of the lesion. Statistical analyses were performed by using SPSS13 software program.

Results: Of 2335 cases of head and neck cancer, 736 cases (59\%) were detected in men and 511 cases $(41 \%)$ were found in women. Squamous cell carcinoma (SCC) $(42.6 \%)$ and Basal cell carcinoma (BCC) $(23.04 \%)$ were the most prevalent types of cancer. These cancers mostly occurred during the seventh and eighth decades of life. The most common locations were the esophagus and cervical lymph nodes.

Conclusion: In the current survey, head and neck cancers comprised $18 \%$ of all the malignancies ( 2335 cases out of a total of 12830 cases), which differs from the results obtained worldwide. This difference may be due to the difference in registry centers and varied risk factors in each country. In our survey, SCC was the most common head and neck malignancy followed by BCC, which is similar to the results of the majority of the related studies. 


\section{Introduction:}

The Annual Congress of the Cancer Institute of Iran has reported that 4500 cases of head and neck cancer are diagnosed annually. ${ }^{(1)} \mathrm{Head}$ and neck cancers, due to their complex anatomical locations, coupled with patients' lack of knowledge about the symptoms of these types of cancers, frequently result in late discovery and diagnosis. Head and neck cancers are common diseases which have not experienced a reduced mortality rate over the last 20 years, despite the availability of new treatments.

Researchers believe that evaluation of the related data could allow early screening of head and neck cancer. Head and neck squamous cell carcinomas (HNSCCs) are the most life-threatening cancers of the head and neck since there are many anatomical complexities in this area of the body. ${ }^{(1-2)} \mathrm{SCC}$ is the most aggressive malignancy accounting for more than $90 \%$ of all the head and neck malignancies. ${ }^{(2-4)}$ If these cancers do not receive appropriate treatment, they will spread to adjacent tissues, organs and cervical lymph nodes or will even metastasize to distant areas such as the lungs, bones, and liver. ${ }^{(1)}$

The prevalence of head and neck cancers greatly varies in different geographical regions, ranging from a few percent in Western countries to $40 \%$ in Southeast Asia. ${ }^{(2)}$ Approximately 6000 people per year die from this type of cancer and the mortality rate depends considerably on ethnicity, gender and age. ${ }^{(1)}$

Considering the mortality caused by head and neck cancers, perception of the frequency and etiology of these cancers, which depend on regional conditions, nutritional habits and genetic differences, may allow researchers in the field to gain significant awareness towards these cancers.

Therefore, we investigated the prevalence of these cancers in Gilan province, Iran, with regards to geographical location, environmental conditions and ethnicity.

\section{Methods and Materials:}

This retrospective and descriptive study was performed during 1999-2008 through data col- lection with regards to various factors, such as age, sex, type and location of the cancer, using the data from the Cancer Registry Center of Gilan province, Iran. The gathered data were evaluated and statistically analyzed by SPSS13 software program, and the results were reported as descriptive statistical indices with a $95 \%$ confidence interval.

\section{Results:}

Over the 10-year period of data collection, 2335 cases of head and neck malignancies were recorded, while a total of 12835 malignant cases were reported by the Cancer Registry Center of Gilan province, Iran. Among 2335 cases of head and neck malignancies, 1372 cases (59\%) occurred in men and 963 cases (41\%) were found in women. SCC and BCC were the most common types of cancer, accounting for $42.6 \%$ and $23.04 \%$ of the reported cases, respectively. Additionally, the highest rates of head and neck cancer occurred during the eighth decade of life, followed by the seventh decade of life. The most common cancer sites observed in this investigation were the esophagus (25.86\%), skin (21\%), thyroid (7\%) and lymph nodes of the head and neck $(7 \%)$.

\section{Discussion:}

In this study, 2335 cases of head and neck cancer, equivalent to $18 \%$ of the total malignancies, were reported over a 10 -year period in Gilan province, Iran. In a 5-year study conducted by Onyango et al, 793 cases of head and neck malignancies were reported, which represented $33 \%$ of all the malignant cases. ${ }^{(5)}$ Additionally, in a 9-year study performed by Izarzugaza et al from 1986 to 1994, 2548 cases of head and neck cancer accounted for $23 \%$ of all the discovered cancer cases. ${ }^{(6)}$ Armando et al during 5 years and Larizadeh et al during 11 years reported the frequency of these cancers to be $10.6 \%$ and $8 \%$, respectively. ${ }^{(7,8)}$ Furthermore, Oji and Chukwuneke reported 81 cases of head and neck cancer during 6 years, which comprised $2.7 \%$ of the overall cancer prevalence. ${ }^{(9)}$ In a 15 -year study, SCC comprised $67.7 \%$ of the carcinomas and $47.8 \%$ of head and neck cancers. ${ }^{(10)}$ 
Ansari recognized SCC, with 38\% prevalence rate, as the second most prevalent head and neck tumor after BCC. ${ }^{(11)}$ Furthermore, Erisen et al and Larizadeh et al reported SCC as the most prevalent head and neck malignancy with $88 \%$ and $77.5 \%$ prevalence rates, respectively. ${ }^{(8,12)}$ In separate studies, Budhy et al and Mehrotra et al showed that the frequency of SCC was equal to $70.7 \%$ and $67 \%$, respectively. ${ }^{(13,14)}$

Our results were similar to the studies which implied that despite the varying percentages, SCC is the most common head and neck cancer in most parts of the world. In addition, we found that the male to female ratio of head and neck cancer was 1.4:1. Other studies have stated male to female ratios of $2: 1,1.8: 1$ and 1.53:1. (10,11,14) $^{2}$

Our survey also demonstrated that the most common cancer location was the esophagus $(25.86 \%)$, followed by skin (21\%), thyroid (7\%) and lymph nodes of the head and neck (7\%). Erisen et al found that the esophagus and larynx $(13.1 \%)$ were the most prevalent sites in the Turkish population. ${ }^{(12)}$ Izarzugaza et al demonstrated that the esophagus $(28 \%)$ and tongue $(6.6 \%)$ were the most common locations of malignancy. ${ }^{(6)}$ Similarly, Ostman et al examined head and neck cancers in Sweden and came to the conclusion that the esophagus $(43 \%)$ and lymph nodes $(21 \%)$ were the most common locations of malignancy. ${ }^{(15)}$ Mirzaei et al and Mafi et al reported that the thyroid and larynx cancers were the most prevalent head and neck malignancies, which confirmed our results. ${ }^{(16,17)}$

Additionally, our results showed that head and neck cancer patients were usually in the eighth $(25 \%)$ and seventh $(21 \%)$ decades of life. Shahsavari et al also studied head and neck cancer patients in Tehran, Iran, and arrived at the same conclusion that the eighth $(27 \%)$ and seventh $(22 \%)$ decades of life were the most common decades for the development of head and neck cancer. ${ }^{(18)}$ Chidzonga reported that malignant neoplasms were most prevalent during the eighth $(34 \%)$ and seventh (29.7\%) decades of life in Zimbabwe. ${ }^{(19)}$ Likewise, Ansari reported that patients who underwent biopsy in Hamedan, Iran, were mostly in their seventh $(42.7 \%)$ and eighth (39.6\%) decades of life. . $^{(1)}$ Mehrotra and colleagues stated that the majority of the patients presented with these cancers in India were in the sixth and eighth decades of life. ${ }^{(14)}$ Ostman et al reported that the majority of head or neck malignancies in Sweden have been diagnosed dur- ing the eighth (41\%) and seventh (36\%) decades. (15) Izarzugaza and colleagues stated that the seventh (34\%), sixth (29\%), and eighth (27\%) decades of life were the most prevalent ages for the diagnosis of head and neck cancers in Spain. ${ }^{(6)}$

\section{Conclusions:}

Head and neck cancers comprised $18 \%$ of all the malignancies in the present study. SCC was the most common head and neck malignancy, followed by BCC as the second most common type of head and neck cancer. These cancers mostly involved the esophagus and metastasized at a higher rate among men than women, with a male to female ratio of 1.4:1. Most head and neck cancer patients were in the eighth and seventh decades of life.

\section{Acknowledgement:}

This article is based on general dentistry thesis No.1276 registered at the dental branch of Islamic Azad University of Tehran.

\section{References:}

1.Elter JR, Patton LL, Strauss RP. Incidence rates and trends for oral and pharyngeal cancer in north Carolina: 1990-1999. Oral Oncology 2005;41(5):470-9.

2.Mehrotra R, Yadav S. Oral squamous cell carcinoma: etiology, pathogenesis and prognostic value of genomic alterations. Indian J Cancer 2006;43(2):60-6. 3.Shahsavari F, Sadri D, Jolehar M, Farzanehnejad R. Epidemiologic Study of the Prevalence of Oral Mucosal Lesions in the Biopsied Samples at Buali and Imam Khomeini Hospitals from 2000 to 2014. J Res Dentomaxillofac Sci 2016;1(1):28-33.

4.Sadri D., Azizi A., Farhadi S., Shokrgozar H., Entezari N. Head and Neck Metastatic Tumors: a Retrospective Survey of Iranian Patients. J Dent (Shiraz) 2015; 16(1):17-21.

5.Onyango JF, Awange DO, Njiru A, Macharia IM. Pattern of occurrence of head and neck cancer presenting at Kenyatta National Hospital, Nairobi. East Afr Med J 2006;83(5):288-91.

6.Izarzugaza MI, Esparza H, Aguirre JM. Epidemiological aspects of oral and pharyngeal cancers in the Basque Country. J Oral Pathol Med 2001;30(9):521-6. 7. Armando A, Bozzetti MC, de Medeiros Zelmanowicz A, Miguel F. The epidemiology of cancer in Angola-results from the cancer registry of the national oncology centre of Luanda, Angola. Ecancermedicalscience. 2015, 9:510.

8.Larizadeh MH, Damghani MA, Shabani M. Epide- 
miological Characteristics of Head and Neck Cancers in Southeast of Iran. Iran J Cancer Prev 2014;7(2):806.

9.Oji C, Chukwuneke FN. Oral cancer in Enugu, Nigeria, 1998-2003. Br J Oral Maxillofac Surg 2007;45(4):298-301.

10.Adeyemi BF, Adekunle LV, Kolude BM , Akang EE, Lawoyin JO. Head and Neck Cancer-A Clinicopathological Study in a Tertiary Care Center. J Natl Med Assoc 2008; 100(6):690-7.

11.Ansari MH. A 13 years statistical evaluation on maxillofacial malignant tumors in Hamedan. J Dent Med 2002;15(4):103-8.

12.Erisen L, Basut O, Tezel I, Onart S, Arat M, Hizalan I, et al. Regional epidemiological features of lip, oral cavity and oropharyngeal cancer. J Environ Pathol Toxicol Oncol 1996;15(2):225-9.

13. Budhy TI, Soenarto SD, Yaacob HB, Ngeow WC. Changing incidence of oral and maxillofacial tumors in East Java, Indonesia, 1987-1992. Part 2: Malignant tumors. Br J Oral Maxillofac Surg 2001;39: 460-4.

14.Mehrotra R, Singh M, Gupta, RK Singh M, Kapoor AK. Trends of prevalence and pathological spectrum of head and neck cancers in North India. Indian J Cancer 2005; 42(2):89-93.

15.Ostman J, Anneroth G, Gustafsson H, Tavelin B. Malignant oral tumors in Sweden 1960-1989.An epidemiological study. Eur J Cancer B Oral Oncol 1995;31B(2):106-12.

16.Mirzaei M, Hosseini SA, Ghoncheh M, Soheilipour F, Soltani S, Soheilipour F, et al.Epidemiology and Trend of Head and Neck Cancers in Iran. Glob J Health Sci 2015;17:8(1):189-93.

17.Mafi N, Kadivar M, Hosseini N, Ahmadi S, Zare-Mirzaie A. Head and neck squamous cell carcinoma in Iranian patients and risk factors in young adults: a fifteen-year study. Asian Pac J Cancer Prev 2012;13(7):3373-8.

18. Shahsavari F, Rahrotaban S , Jolehar M. Epidemiologic study of head and neck cancers in Tehran cancer center (Iran). Int J Recent Sci Res 2016;7(5):10797801.

19.Chidzonga MM. Oral malignant neoplasia: A survey of 428 cases in two Zimbabwean hospitals. Oral Oncol 2006;42(2):177-83. 